\title{
Pd/TiO2-WO3 Photocatalysts for Hydrogen Generation from Water-Methanol Mixtures
}

\section{Author names and affiliation:}

Sandra Yurani Toledo Camacho, S.Y. Toledo-Camacho ${ }^{\text {a }}$

a Departament d' Enginyeria Química, Universitat Rovira i Virgili, Av. Països Catalans, 26, Tarragona 43007, Spain

*Corresponding author e-mail: sandrayurani.toledo@urv.cat

Ana Rey, A. Rey ${ }^{b}$

${ }^{\text {b }}$ Departamento de Ingeniería Química y Química Física, Universidad de Extremadura, Av. Elvas s/n, 06006 Badajoz, Spain e-mail address: anarey@unex.es

María Dolores Hernández-Alonso, D.M. Hernández-Alonso ${ }^{\text {b, } 1}$

${ }^{\text {b }}$ Departamento de Ingeniería Química y Química Física, Universidad de Extremadura, Av. Elvas s/n, 06006 Badajoz, Spain e-mail address: lolihza@gmail.com

\section{Jordi Llorca, J. Llorca ${ }^{\mathrm{c}}$}

c Institut de Tècniques Energètiques, Barcelona Research Center in Multiscale Science and Engineering, and Department of Chemical Engineering, Universitat Politécnica de Catalunya, 08019 Barcelona, Spain

e-mail address: jordi.llorca@upc.edu

\section{Francisco Medina Cabello, F. Medina ${ }^{a}$}

a Departament d' Enginyeria Química, Universitat Rovira i Virgili, Av. Països Catalans, 26, Tarragona 43007, Spain

e-mail address: francesc.medina@urv.cat

\section{Sandra Contreras Iglesias, S. Contreras a}

a Departament d' Enginyeria Química, Universitat Rovira i Virgili, Av. Països Catalans, 26, Tarragona 43007, Spain e-mail address: sandra.contreras@urv.cat

\footnotetext{
Abstract

Solar light is inexhaustible; therefore, to take advantage of this energy, it is necessary to develop materials capable of absorbing in the widest range of the solar spectra. Although $\mathrm{TiO}_{2}$ is one of the most studied photocatalysts, it just absorbs in the UV range. With the purpose of increasing this absorption light towards visible range, different materials such as $\mathrm{Pd}_{\text {and }} \mathrm{WO}_{3}$ have been supported on bare $\mathrm{TiO}_{2}$, to study their photocatalytic properties for hydrogen generation from water-methanol mixtures under UVA and solar irradiation. Several parameters on the hydrogen production such as the amount of Pd, the catalyst amount and the influence of the water matrix have been studied. These catalytic materials were characterized by means of inductively coupled plasma with an optical emission spectrophotometer, nitrogen adsorption-desorption isotherms, X-ray diffraction, high resolution transmission electron microscopy, X-ray photoelectron spectroscopy and diffuse reflectance UV-Vis spectroscopy. Hydrogen evolution was monitored by on-line gas chromatography. The incorporation of a small amount of Pd (lower than 0.01 wt \%) produced an important increase in the hydrogen production. Furthermore, the addition of $\mathrm{WO}_{3}$ on the bare titania also produced an increase in the hydrogen generation. The highest quantum efficiency obtained in this work under solar radiation was $7.7 \%$ by the catalyst based on palladium supported on the nanotubes of titanium dioxide and tungsten trioxide $\left.\left(\mathrm{Pd} / \mathrm{NT}^{-\mathrm{WO}}\right)_{3}\right)$ using an aqueous solution of methanol (50 vol.\%).
} 
${ }^{1}$ Present Address: Repsol Technology Center, Agustín de Betancourt, s/n, 28935 Móstoles, Madrid, Spain

Abbreviations: NT, nanotubes of $\mathrm{TiO}_{2} ; \mathrm{P} 25$, commercial $\mathrm{TiO}_{2} ;$ Eg, Energy gap

Keywords: photocatalysis; hydrogen; low palladium addition; sacrificial agents, quantum efficiency

\section{Graphical abstract}

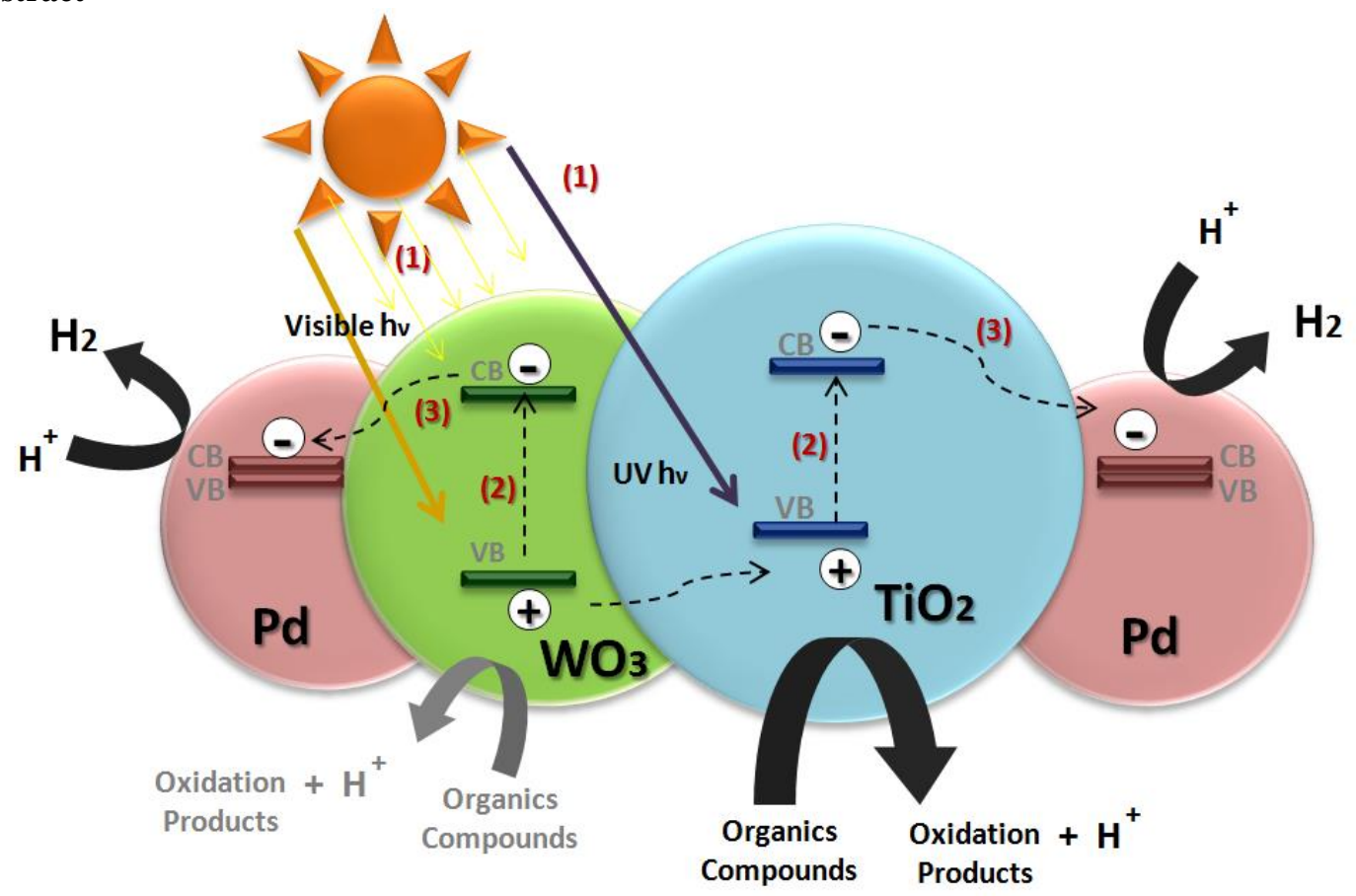

\section{Highlights:}

- An efficient catalyst for hydrogen production under solar radiation has been obtained by doping Pd nanoparticles by photodeposition over a powdered support containing $\mathrm{TiO}_{2}$ and $\mathrm{WO}_{3}$.

- The addition of small Pd particles by photodeposition produces a strong increase in the hydrogen production decreasing the recombination of the electron hole pairs.

- The addition of $\mathrm{WO}_{3}$ nanoparticles allows the absorption of light of the catalysts in the visible region.

\section{Introduction}

The solar energy is one of the most abundant energy source on earth and its inexhaustible supply make it a focus of investigation aiming to found technologies capable of capturing, converting and storing efficiently this energy. Among these technologies, photocatalytic hydrogen generation seems to be a potential alternative for this process. Hydrogen is an energy carrier, is highly efficient, stocks three times more energy than the same amount of natural gas, easy to convert to other kind of energies and also, hydrogen is an environmentally friendly energy carrier because its combustion produces only water [1, 2, 3].

Since 1972, when Fujishima and Honda found out the water splitting into hydrogen and oxygen on a titanium dioxide $\left(\mathrm{TiO}_{2}\right)$ electrode irradiated under ultraviolet light (UV) [4], the photocatalytic hydrogen generation seems to have become a promising solution to overcome problems related to fuels and environmental pollution. Moreover, to take advantage of the solar energy to produce hydrogen, it is necessary to satisfy, at least, two requirements: (i) to develop materials capable of absorbing in the widest range of the solar electromagnetic spectra and also (ii) that those materials have the capacity to produce, mainly, hydrogen.

Hydrogen production on semiconductor materials is mainly affected by the quantity of photogenerated electrons in relation to the incident photons. Thereby, any process, related to the consumption or generation of electrons, influences directly on low hydrogen efficiencies [5]. These low efficiencies toward hydrogen in photocatalytic processes are commonly caused by three reasons: (i) reverse reaction between $\mathrm{H}_{2}$ and $\mathrm{O}_{2}$; (ii) photogenerated electron-holes recombination $\left(\mathrm{e}^{-}-\mathrm{h}^{+}\right)$and (iii) limited capacity 
in light absorption.

In regard to the reverse reaction between $\mathrm{H}_{2}$ and $\mathrm{O}_{2}$, these gases are produced during the photocatalytic water splitting, that occurs when water molecules react with the photogenerated holes in the valence band, so, oxygen $\left(1 / 2 \mathrm{O}_{2}\right)$ and hydrogen ions $\left({ }^{+} \mathrm{H}\right)$ are produced $[6,7]$. Then, the hydrogen ions $\left({ }^{+} \mathrm{H}\right)$, instead of reacting with photogenerated electrons in the conduction band, they react in backward with the oxygen to produce again water molecules. To overcome this reverse reaction, it has been proposed to use electron donor, which can be co-catalysts or sacrificial agents [7,8] to trap the photogenerated holes and increase the probability of reaction between ${ }^{+} \mathrm{H}$ and the conduction band electrons of the semiconductor material. However, the yields of cocatalysts as $\mathrm{IrO}_{2}\left(\mathrm{RuO}_{\mathrm{x}}\right)$ [7], $\mathrm{Au}$ [9], $\mathrm{Rh}$ [10] or $\mathrm{CuO}$ [11] are still low. On the other hand, organic compound are excellent sacrificial agents due to the fact that most of the organic functional groups have an oxidation potential less positive than the valence band edges of the most common semiconductors materials [8], it means that by photocatalytic processes not only hydrogen can be obtained, but also organic compounds could be oxidized.

Concerning the electron-holes recombination, when a photon, with an energy higher than the band-gap of the semiconductor material, interacts on the photocatalyst surface, it transfers energy to the electrons in the valence band. The electrons "jump" to the conduction band where it can react subconsequently with molecules adsorbed on the catalyst surface. This last reaction should happen in less than (10-100) nano-seconds $[12,13]$. On the contrary, the recombination takes place, releasing energy in light or heat form [14]. Accordingly, in order to increase the lifetime of the photogenerated electron-hole pair, it has been proposed the incorporation of doping and/or loading co-catalysts to the bare photocatalyst. The incorporation of doping or loading co-catalysts to reduce the recombination probabilities can also improves the limited capacity in solar light absorption (visible range 390-780 $\mathrm{nm})$. With this objective, different materials have been incorporated to the bare $\mathrm{TiO}_{2}$ : non-metal doping (N, F, C and S) [12, 15], noble metal loading (Ru, Rh, Pd, Ag, Pt and Au) [10, 16, 17], transition metal oxides (V-, Mn-, Fe-, Co-, Ni-, Cu-, Zn-, Zr-, Nb-, Mo-, Ta-, W- oxides) [12, 18], metal oxides (Ga-, Ge-, In-, Sn- and Sb- oxides) [12] and metal sulfides $\left(\mathrm{CdS}, \mathrm{ZnS} \mathrm{Bi}_{2} \mathrm{~S}_{3}\right)$ [12, 19, $20,21,22]$.

Under visible light, the quantum yields of the photocatalysts toward hydrogen, hardly reaches $10 \%$. Most of these catalysts include transition noble metals ( $\mathrm{Au}, \mathrm{Pt}, \mathrm{Rh}$ and $\mathrm{Pd}$ ) as co-catalysts of $\mathrm{TiO}_{2}[1,10,16,20,23]$. So, regard to the hydrogen production under visible irradiation by using sacrificial agents, we see the need of moving on the study of photocatalytic materials with a narrower band-gap, more positive valence and conduction band levels than $\mathrm{TiO}_{2}$ to oxidize the highest amount of organic compound as possible, pumping the photogenerated electrons out of the $\mathrm{TiO}_{2}$ conduction band, respectively.

In this sense, tungsten trioxide $\left(\mathrm{WO}_{3}\right)$ seems to be a good co-catalyst because of its light absorption properties in wavelength up to $480 \mathrm{~nm}$, relatively narrow band-gap (around 2,8 eV) and stability and harmlessness in acidic and oxidative conditions [2, 24, 25]. Nevertheless, $\mathrm{WO}_{3} / \mathrm{TiO}_{2}$ without being doped has shown low photocatalytic activity toward hydrogen formation [2, 26].

In this paper, hydrogen production from water-methanol mixtures is investigated on a series of catalysts based on $\mathrm{Pd} / \mathrm{TiO}_{2}-\mathrm{WO}_{3}$ under visible and UVA light, where palladium is added in very small amount (around 0.01 wt.\%) in order to produce cheaper catalysts for industrial purpose. Palladium (Pd) was selected as co-catalyst as supported Pd has demonstrated to be a good promoter of photocatalytic activity, which could work as electron trapping [10, 26,27] and also, because among the noble metals, $\mathrm{Pd}$ is the most reactive one and has a remarkable capacity for hydrogen absorption [28].

\section{Experimental section}

\subsection{Materials}

$\mathrm{P} 25-\mathrm{WO}_{3}$ and nanotubes of titania (NT) containing $\mathrm{WO}_{3}\left(\mathrm{NT}-\mathrm{WO}_{3}\right)$ supports were synthesized according to a previous work [24]. Briefly, NT were prepared from Aeroxide $\mathrm{TiO}_{2} \mathrm{P} 25$ following this procedure: $1 \mathrm{~g}$ of P25 plus $70 \mathrm{ml}$ of $\mathrm{NaOH}(10 \mathrm{M})$ were stirred for 30 minutes. Then, the mixture was treated at $130{ }^{\circ} \mathrm{C}$ for $48 \mathrm{~h}$ in a Teflon-lined autoclave. The obtained powders were washed 
several times with diluted $\mathrm{HCl}$, and dried at $100{ }^{\circ} \mathrm{C}$ overnight. Then the samples were calcined in air atmosphere $\left(350{ }^{\circ} \mathrm{C}\right)$ for $3 \mathrm{~h}$. The deposition of $\mathrm{WO}_{3}$ nanoparticles over $\mathrm{P} 25$ and NT were performed by precipitation of $\mathrm{H}_{2} \mathrm{WO}_{4}$ solution with ammonia. On the other hand, Titanium (IV) oxide, Aeroxide P25 (Acros Organics) (XRD analysis: $87.6 \%$ anatase and 12.4 \% rutile; $16.9-30 \mathrm{~nm}$ primary particle size) and Titanium dioxide, $\mathrm{TiO}_{2}$-anatase (Probus) (XRD analysis: $88.3 \%$ anatase and 11.6\% rutile; $53.4-85 \mathrm{~nm}$ primary particle size) were used as support for $\mathrm{Pd} / \mathrm{P} 25$ and $\mathrm{Pd} / \mathrm{TiO}_{2}$-anatase catalysts, respectively. Tungstic acid $\left(\mathrm{H}_{2} \mathrm{WO} \mathrm{O}_{4}\right)$ (Aldrich, $99 \%$ ) was used as the starting material for $\mathrm{WO}_{3}$ synthesis. Palladium (II) Chloride ( $\mathrm{PdCl}_{2}$, Johnson Matthey, metal purity $59.66 \%$ ) diluted in hydrocloric acid $(\mathrm{HCl}) 37 \%$ (Analytical reagent from Fisher) was used for Pd incorporation on these supports. For water-methanol mixtures, two kind of water were used: tap water and milliQ water. Methanol was supplied by Sigma Aldrich (99.8\% of purity).

\subsection{Catalysts preparation}

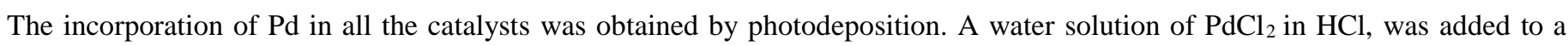
glass flask and stirred by some minutes. Then, the catalytic supports $\left(\mathrm{P} 25-\mathrm{WO}_{3}, \mathrm{NT}-\mathrm{WO}_{3}, \mathrm{TiO}_{2}\right.$-anatase, $\mathrm{P} 25$ or $\left.\mathrm{WO}_{3}\right)$ was added under continuous stirring. Afterward, the system, under continuous stirring, was deaerated with argon (50 ml/min) for $50 \mathrm{minu}$ tes and then irradiated with a UV lamp $\left(\lambda_{\max } \sim 365 \mathrm{~nm}, 6 \mathrm{~W}\right)$ overnight (around $\left.14 \mathrm{~h}\right)$. After irradiation, the solid particles were recovered by filtration, washed several times with distilled water and dried at room temperature under vacuum. In the text the abbreviation $2 \mathrm{w}$ and $4 \mathrm{w}$ refers to 2000 and $4000 \mathrm{ppm}$ of catalytic support in the photodeposition solution.

\subsection{Characterization}

NT- $\mathrm{WO}_{3}$ and $\mathrm{P} 25-\mathrm{WO}_{3}$ supports were characterized by inductively coupled plasma (ICP), BET surface area (S $\mathrm{SET}_{\mathrm{BET}}$ and pore volume ( $\mathrm{V}_{\mathrm{PORE}}$ ) using nitrogen adsorption-desorption isotherms at $-196{ }^{\circ} \mathrm{C}$. Their structural characterization (morphology and the amount of anatase and rutile $\mathrm{TiO}_{2}$ phases in both supports) was performed employing X-ray diffraction (XRD) and transmission electron microscopy (TEM). The band-gap was determined by UV-Vis diffuse reflectance spectra. More details about the characterization of $\mathrm{NT}-\mathrm{WO}_{3}$ and $\mathrm{P} 25-\mathrm{WO}_{3}$ supports can be found in the reference [24].

The palladium content of the catalysts was analyzed by ICP-OES: inductively coupled plasma with an optical emission spectrophotometer (ICP-OES, Spectro Arcos FHS-16). BET surface area and pore volume of the photocatalysts were determined by nitrogen adsorption-desorption isotherms obtained at $-196{ }^{\circ} \mathrm{C}$ using an Quadrasorb SI Models 4.0 using QuadraWin Software (v. 5.0+newer). Before the sample analysis, the photocatalysts were outgassed at $150{ }^{\circ} \mathrm{C}$ for $18 \mathrm{~h}$ under vacuum (6 mTorr) in the instrument pre-chamber to eliminate chemisorbed volatile species.

XRD measurements were made using a Siemens D5000 diffractometer (Bragg-Brentano parafocusing geometry and vertical $\theta-\theta$ goniometer) fitted with a curved graphite diffracted-beam monochromator, incident and diffracted-beam Soller slits, a $0.06^{\circ}$ receiving slit and scintillation counter as a detector. The angular $2 \theta$ diffraction range was between 5 and $70{ }^{\circ}$. The data were collected with an angular step of $0.05^{\circ}$ at 3 seconds per step and sample rotation. $\mathrm{Cu}_{\mathrm{k} \alpha}$ radiation was obtained from a copper $\mathrm{X}$ ray tube operated at $40 \mathrm{kV}$ and $30 \mathrm{~mA}$. The samples were also analysed from 35 to $52^{\circ} 2 \theta$, using angular step of $0.03^{\circ}$ at $12 \mathrm{~s}$ per step, in order to enhance the signal/noise ratio.

High resolution - transmission electron microscopy (HRTEM) analyses were carried out with a JEOL 2010F instrument equipped with a field emission source. The point-to-point resolution was $0.19 \mathrm{~nm}$ and the resolution between lines was $0.14 \mathrm{~nm}$. The XPS spectra were acquired in a VG Escalab 200R electron spectrometer equipped with a hemispherical electron analyzer, operating in a constant pass energy mode, and a non-monochromatic $\mathrm{Mg}-K \alpha(h v=1253.6 \mathrm{eV}, 1 \mathrm{eV}=1.603 \times 10-19 \mathrm{~J})$. X-ray source was operated at $10 \mathrm{~mA}$ and $1.2 \mathrm{kV}$. The angle of the incident photon beam was $45^{\circ}$ with respect to the normal of the sample. The background pressure in the analysis chamber was kept below $7 \times 10^{-9}$ mbar during data acquisition. The binding energy (BE 
$\mathrm{C} 1 \mathrm{~s}=284.9 \mathrm{eV}$ ) of adventitious $\mathrm{C} 1$ was used as reference. A Shirley background subtraction was applied and GaussianLorentzian product functions were used to approximate the line shapes of the fitting components.

Band gap values were determined by diffuse reflectance UV-Vis (DR-UV-Vis) of the solids, measured by a UV-2410 PC spectrometer with integrating Sphere attachment: SHIMADZU ISR-240, converting it into absorbance using the Kubelka-Munk function [Photon energy*Absorbance] ${ }^{1 / 2}$ versus the Photon energy and extrapolation to $\mathrm{y}=0$ of the linear regression.

\subsection{Photocatalytic hydrogen Production}

Photocatalytic hydrogen production tests were carried out in two different reaction systems with continuous stirring. One of the systems consisted in a borosilicate reactor $(750 \mathrm{ml})$ with a wider shape inside of a solar simulator chamber (SUNTEST CPS+) with a Xe lamp at the top of the chamber $\left(300-800 \mathrm{~nm} ; 250 \mathrm{~W} / \mathrm{m}^{2}, \mathrm{I}_{250-450 \mathrm{~nm}}: 6.5 \times 10^{-4}\right.$ Einstein/min). The second system consisted on a vertical glass reactor $(300 \mathrm{ml})$ placed inside a white methacrylate chamber equipped with four UVA lamps arranged in each one of the inner walls of the chamber in vertical position $\left(300-400 \mathrm{~nm} ; 15 \mathrm{~W} / \mathrm{lamp}, \mathrm{I}_{250-450 \mathrm{~nm}}: 8.3 \times 10^{-5}\right.$ Einstein $\left./ \mathrm{min}\right)$.

A mass flow controller (Alicat scientific MC-50SCCM-D/5M) was used to introduce argon as the carrier gas through the reactor and to introduce the hydrogen produced to an on-line gas chromatography (Shimadzu, GC-14B, with a TCD detector and Carbosieve SII 100/120, 3 m 1/8" SS column). The hydrogen production reaction was performed without adjusting the pH and without control of temperature $\left(25-35^{\circ} \mathrm{C}\right)$.
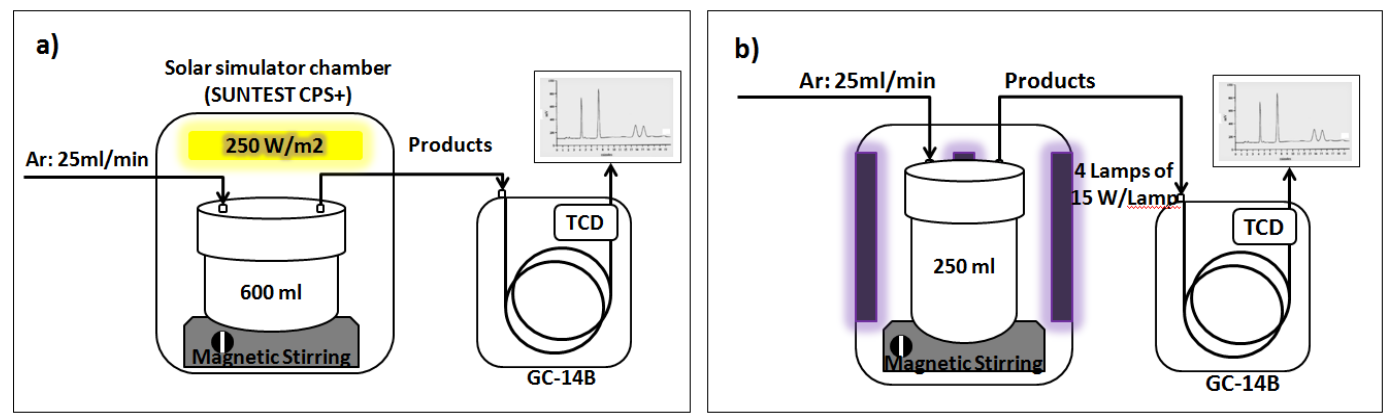

Figure 1. Experimental set up of photocatalytic hydrogen generation under: a) Solar simulated light (300-800 nm; $250 \mathrm{~W} / \mathrm{m}^{2}$, I $250-450 \mathrm{~nm}: 6.5 \times 10^{-}$

${ }^{4}$ Einstein/min) and b) UVA light (300-400 nm; 4 lamps of $15 \mathrm{~W} / \mathrm{lamp}, \mathrm{I} 250-450 \mathrm{~nm}: 8.3 \times 10^{-5}$ Einstein/min)

In a typical photocatalytic experiment, either under visible or UVA light, the reactor was loaded with an aqueous solution of methanol $(5,10,25$ or 50 vol.\%) and different amount of catalysts $(500,333,167$ or 83 ppm). Then, the reactor was placed inside the solar box or the UVA box, and the solution was bubbled with argon $(50 \mathrm{ml} / \mathrm{min})$ around 60 minutes to remove the air inside the reactor and the gas line. The reactor remained under irradiation for $185 \mathrm{~min}$ and every 15 minutes the gas sample was automatically injected to the chromatograph.

\section{Results and discussion}

\subsection{Characterization of the photocatalysts}

Some of the features concerning the characterization of photocatalytic materials used in this article are shown in Table 1. The objective was the introduction of a very low amount of Pd (around $0.01 \mathrm{wt} \%$ ) in order to see the effect of small particles of Pd on the hydrogen generation. NT, P25, pure anatase phase as well as the incorporation of $\mathrm{WO}_{3}$ in these supports have been studied. Table 1 shows the amount of Pd determined by ICP-OES of the different samples. $\mathrm{S}_{\mathrm{BET}}$, $\mathrm{V}_{\mathrm{PORE}}$ and band gap energy (Eg) with the corresponding wavelength are also included in Table 1.

Table 1. List of catalysts used in this study and some of their features related to characterization results

\begin{tabular}{|c|l|l|l|l|l|l|}
\hline Catalyst & Pd wt \% (ICP-OES) & Pd Particle size $(\mathrm{nm})$ by TEM & S $_{\text {BET }}\left(\mathrm{m}^{2} \mathrm{~g}^{-1}\right)$ & Total VPore $\left(\mathrm{cm}^{3} \mathbf{g}^{-1}\right)$ & $\mathbf{E}_{\mathrm{g}}(\mathrm{eV})$ & $\lambda(\mathrm{nm})$ \\
\hline
\end{tabular}




\begin{tabular}{|c|c|c|c|c|c|c|}
\hline $\mathrm{Pd} / \mathrm{NT}-\mathrm{WO}_{3}$ & 0.013 & $<2$ & 94.13 & 0.3691 & 2.94 & 392 \\
\hline $\mathrm{Pd} / \mathrm{P} 25-\mathrm{WO}_{3}$ & 0.011 & $<2$ & 58.02 & 0.3407 & 3.06 & 383 \\
\hline $\mathrm{Pd} / \mathrm{P} 25$ & 0.0092 & $5-7$ & 55.16 & 0.3960 & 3.08 & 3.79 \\
\hline $\mathrm{Pd} / \mathrm{TiO}_{2}$-anatase & 0.0072 & - & 11.07 & 0.0856 & 3.11 & 377 \\
\hline $\mathrm{NT}-\mathrm{WO}_{3}$ & - & - & 104.64 & 0.3890 & 2.97 & 385 \\
\hline $\mathrm{P} 25-\mathrm{WO}_{3}$ & - & - & 58.81 & 0.3690 & 3.08 & 381 \\
\hline $\mathrm{P} 25$ & - & - & 54.69 & 0.2635 & 3.10 & 376 \\
\hline $\mathrm{TiO}_{2}$-anatasa & - & - & 9.81 & 0.0575 & 3.14 & 375 \\
\hline
\end{tabular}

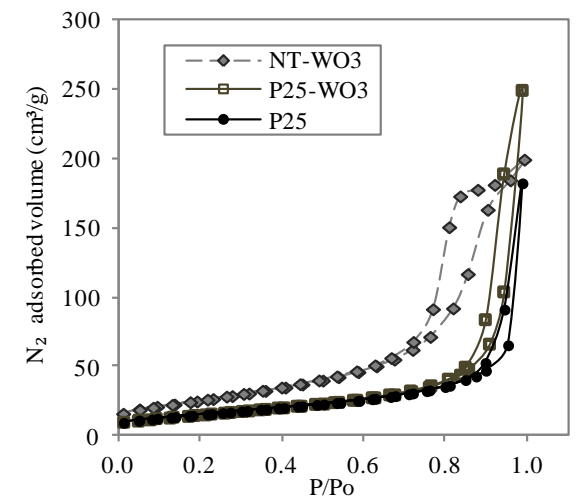

Figure 2. $\mathrm{N}_{2}$ adsorption-desorption isotherms of the catalytic supports

Fig. 2 shows $\mathrm{N}_{2}$ adsorption-desorption isotherms for $\mathrm{NT}-\mathrm{WO}_{3}, \mathrm{P} 25-\mathrm{WO}_{3}$ and $\mathrm{P} 25$ supports. From the results, porous materials with type IV isotherms were observed, containing $\mathrm{H} 2$ type of hysteresis loop for $\mathrm{NT}-\mathrm{WO}_{3}$ and $\mathrm{H} 3$ type of hysteresis loop for $\mathrm{P} 25-$ $\mathrm{WO}_{3}$ and $\mathrm{P} 25$ supports according to IUPAC [29]. Regarding P25- $\mathrm{WO}_{3}$ and P25, their narrow hysteresis loops can indicate that the shape of the pores are in a slot form. On the other hand, the hysteresis loop for the $\mathrm{NT}-\mathrm{WO}_{3}$ sample is wider. That means that the porous of $\mathrm{NT}-\mathrm{WO}_{3}$ are likely more in a narrow necks and wide body's way (ink bottle). Fig. 3 shows $\mathrm{N}_{2}$ adsorption-desorption isotherms for $\mathrm{NT}-\mathrm{WO}_{3}, \mathrm{P} 25-\mathrm{WO}_{3}$ and $\mathrm{P} 25$ after the Pd was deposited. There is not any important change in the pore structure of these materials with respect to the supports. 


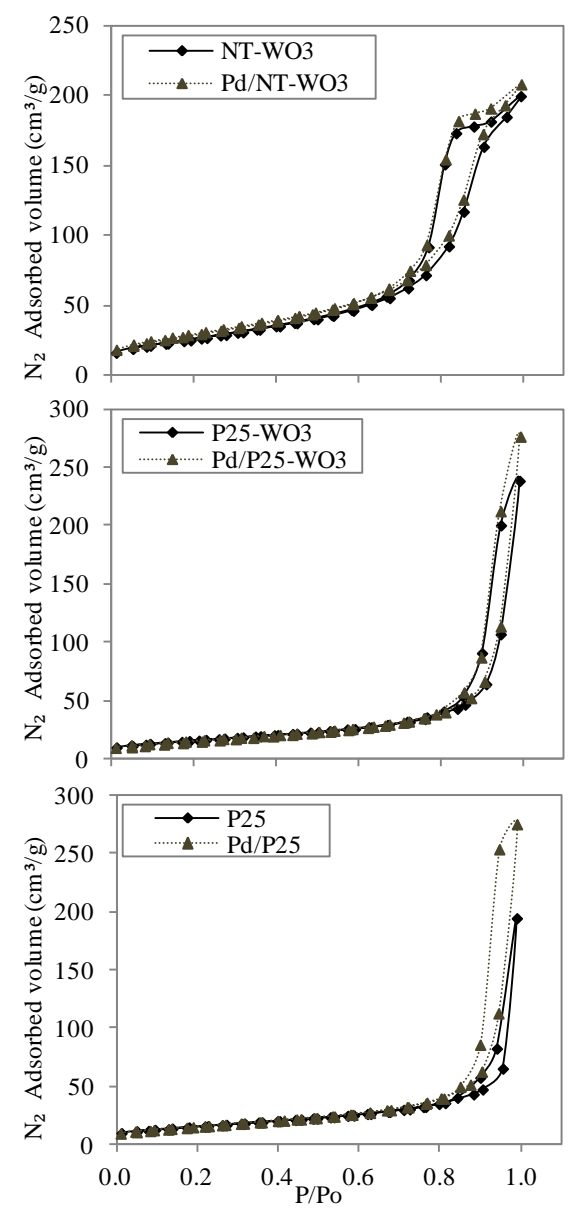

Figure 3. $\mathrm{N}_{2}$ adsorption-desorption isotherms for a) $\mathrm{Pd} / \mathrm{NT}-\mathrm{WO}_{3}$ b) $\mathrm{Pd} / \mathrm{P} 25-\mathrm{WO}_{3}$ and c) $\mathrm{Pd} / \mathrm{P} 25$

From physisorption analysis, $\mathrm{S}_{\mathrm{BET}}$ and $\mathrm{V}_{\mathrm{PORE}}$ were determined (Table 1). For NT- $\mathrm{WO}_{3}\left(104.6 \mathrm{~m}^{2} / \mathrm{g}\right.$ and $0.4541 \mathrm{~cm}^{3} / \mathrm{g}$ ), when Pd is photodeposited, the values of $S_{\mathrm{BET}}\left(94.13 \mathrm{~m}^{2} / \mathrm{g}\right)$ and $\mathrm{V}_{\mathrm{PORE}}\left(0.3691 \mathrm{~m}^{3} / \mathrm{g}\right)$ were slightly reduced. The Pd nanoparticles could close some pores and fill others, therefore the specific area is reduced and also their pore volume. Looking at the hysteresis loop (Fig. 3 (a)), Pd/NT- $-\mathrm{WO}_{3}$ has the same shape of pore structure than $\mathrm{NT}-\mathrm{WO}_{3}$. Therefore, it can be concluded that the Pd nanoparticles could partially occlude the entrance of the pores but without producing the plugging. Consequently, the pore structure is conserved but the pore volume and the surface area decreased. Similar behaviour has been observed for all the catalysts.

In the case of P25 similar $\mathrm{S}_{\mathrm{BET}}$ is obtained for the support as well as after Pd deposition. This is probably because the presence of bigger Pd nanoparticles $(5-7 \mathrm{~nm})$ that are probably located outside of the pores.

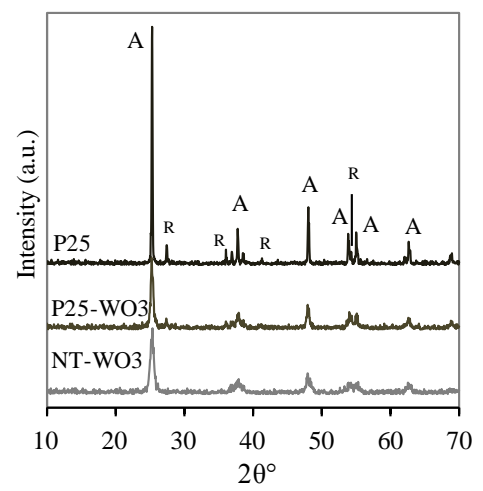

Figure 4. $\mathrm{XRD}$ patterns of $\mathrm{P} 25, \mathrm{P} 25-\mathrm{WO}_{3}$ and $\mathrm{NT}-\mathrm{WO}_{3}$ supports 


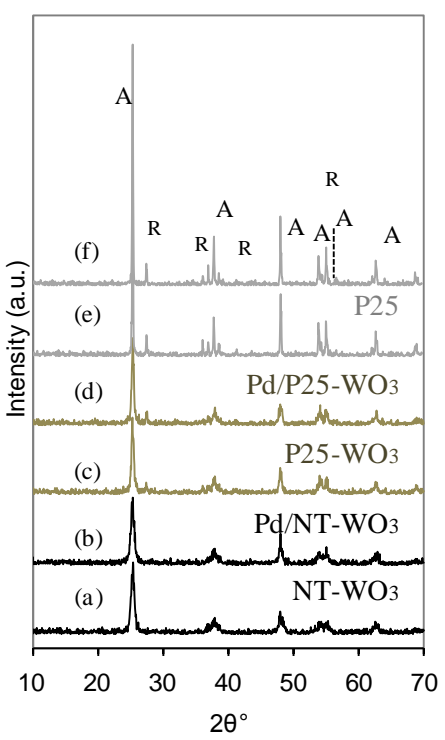

Figure 5. XRD patterns. a) NT- $-\mathrm{WO}_{3}$; b) $\mathrm{Pd} / \mathrm{NT}-\mathrm{WO}_{3}$ c) $\mathrm{P} 25-\mathrm{WO}_{3}$ d) $\mathrm{Pd} / \mathrm{P} 25-\mathrm{WO}_{3}$ e) $\mathrm{P} 25$; f) $\mathrm{Pd} / \mathrm{P} 25$

Fig. 4 shows the X-ray diffraction patterns for $\mathrm{NT}-\mathrm{WO}_{3}, \mathrm{P} 25-\mathrm{WO}_{3}$ and P25 supports and after the deposition of Pd. All three supports exhibited similar diffraction lines referable to anatase phases (A). In the case of rutile phase (R), only $\mathrm{P}_{25}$ and $\mathrm{P} 25-\mathrm{WO} 3$ exhibited it. Concerning this absence of rutile phase on $\mathrm{NT}-\mathrm{WO}_{3}$, it is due to the synthesis protocol performed to obtain NT [24]. Regarding the absence of peaks referable to $\mathrm{WO}_{3}$, Rey and collaborators [24] explain that it could be due to its low amount (around 5 wt.\%). Therefore, the incorporation of $\mathrm{WO}_{3}$ species has not any significant effect on the $\mathrm{TiO}_{2}$ structure.

Regarding the effect of Pd photodeposition method on the crystalline phases of the supports (see Fig. 5) no effect is observed. Furthermore, due to the low amount of Pd in the sample no diffraction line corresponding to Pd is detected. This is also in concordance with TEM results that indicate the presence of smaller Pd nanoparticles, which could be even at atomic size level.

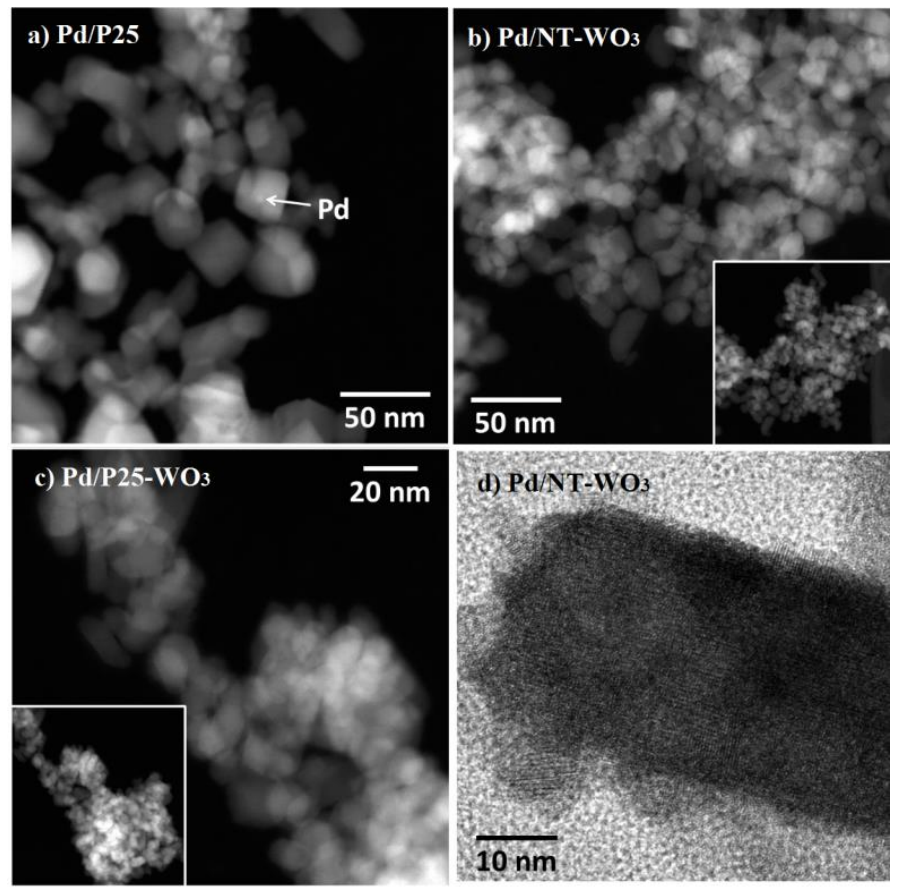

Figure 6. TEM images. STEM-HAADF images for a) Pd/P25; c) Pd/NT-WO 3 and e) Pd/P25-WO 3 and HRTEM image for b) Pd/P25; d) Pd/NT$\mathrm{WO}_{3}$

From Fig. 6 (a), it is possible to see that the sample containing Pd deposited on P25 is constituted by titania crystallites and some Pd nanoparticles of 5-7nm in size. For the samples that contains $\mathrm{WO}_{3}$ on NT (sample Pd/NT-WO 3 , Figure 6 (b) or on P25 (sample 
$\mathrm{Pd} / \mathrm{P} 25-\mathrm{WO}_{3}$, Figure 6 (c), Pd particles are not identified neither by STEM of HRTEM, which means that they are likely very small in size $(<2 \mathrm{~nm}$ in size), so they escape STEM detection with the microscope used. This fact indicates that the addition of $\mathrm{WO}_{3}$ produces a very high dispersion of the $\mathrm{Pd}$. In TEM images we can see that the samples are constituted by $\mathrm{TiO}_{2}$ particles of about $15-40 \mathrm{~nm}$ in size well dispersed, which are mostly decorated by other small (less than $10 \mathrm{~nm}$ ) $\mathrm{WO}_{3}$ crystallites.

Fig. 7 shows the surface chemical composition analysed by XPS for Pd/NT-WO 3 and Pd/P25 catalysts. From the complete spectra for all the catalysts of $\mathrm{Pd} / \mathrm{P} 25$ illustrated in Fig. 7 (a) and (c) is verified the presence of $\mathrm{O}$, Ti and $\mathrm{C}$ with the $\mathrm{O} 1 \mathrm{~s}, \mathrm{Ti} 2 \mathrm{p}, \mathrm{C} 1 \mathrm{~s}$ and Ti 3p peaks at $531 \mathrm{eV}, 460 \mathrm{eV}, 285 \mathrm{eV}$ and $38 \mathrm{eV}$, respectively. Pd 3d XPS analysis for Pd/NT-WO 3 and Pd/P25 are presented in Fig. 7 (b) and (d). For both samples, it is difficult to see very clear Pd peaks due to the low contents of Pd. However, it is possible to see two small prominences at around $336.7 \mathrm{eV}$ and $341.9 \mathrm{eV}$, which are characteristic for metallic $\mathrm{Pd}(\mathrm{Pd} 5 / 2$ and $\mathrm{Pd} 3 / 2$ transitions, respectively) and correspond to $\mathrm{Pd}$ (II) species, which likely can be $\mathrm{PdO}$ or $\mathrm{Pd}(\mathrm{OH})_{2}[30]$.

The optical band gap was determined by means Tauc's plot for indirect semiconductors ([Photon energy* Absorbance ${ }^{1 / 2}$ versus the Photon energy) obtained from diffuse reflectance spectra. Barium sulphate $\left(\mathrm{BaSO}_{4}\right)$ was used as standard. The diffuse reflectance spectrum was converted into absorbance using the Kubelka-Munk function. The band gap results are summarized in Table 1 together with the wavelength and absorption edge. The band gap values (Eg) for $\mathrm{P} 25, \mathrm{NT}-\mathrm{WO}_{3}$ and $\mathrm{P}_{25}-\mathrm{WO}_{3}$ are $3.10,2.97$ and $3.08 \mathrm{eV}$, respectively.

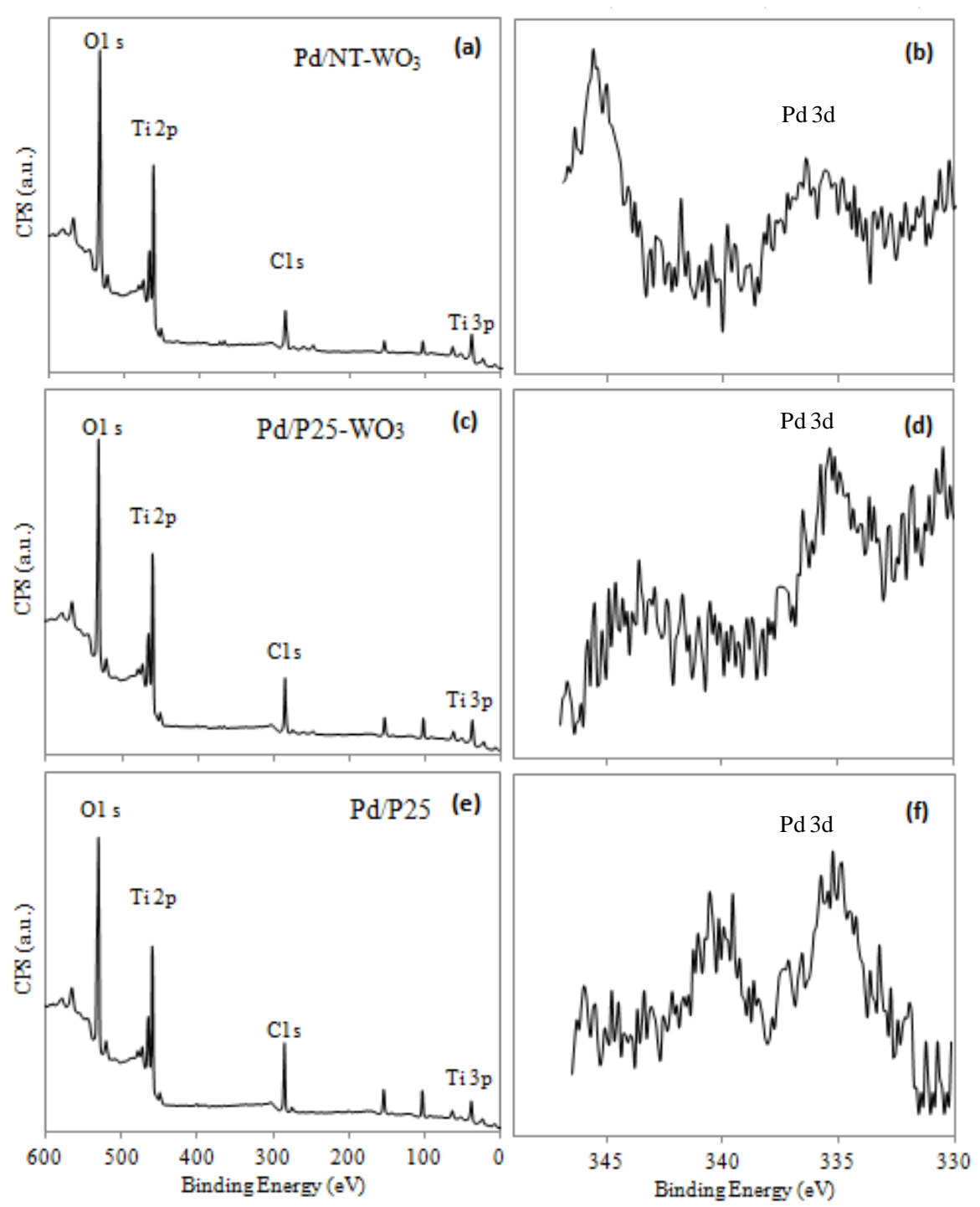

Figure 7. XPS full spectra of the catalysts (a, c and e). High-resolution XPS spectra of Pd $3 d(b, d$ and f) spectral region of Pd/NT-WO $\mathrm{Pd} / \mathrm{P} 25-\mathrm{WO}_{3}$ and $\mathrm{Pd} / \mathrm{P} 25$ catalysts. 
The DR-UV-Vis spectra (Fig. 8) showed a higher optical absorbance near $400 \mathrm{~nm}$ for all the catalysts when the Pd is incorporated.

From Table 1 is possible to observe that the incorporation of Pd produces a slight decrease in the band gap and higher wavelength (nm) for all the catalysts. Pd/NT- $\mathrm{WO}_{3}$ showed the lowest band gap energy and higher wavelength (2.94 Eg, $\left.393 \mathrm{~nm}\right)$. Nevertheless, the band gap values are comparable to the literature for similar materials [24]. Some authors indicate that the incorporation of noble metals to semiconductors materials enhances light absorption toward visible region that can be attributed to a characteristic absorption of surface excitation due to plasmons of the metal nanoparticles [31][32].

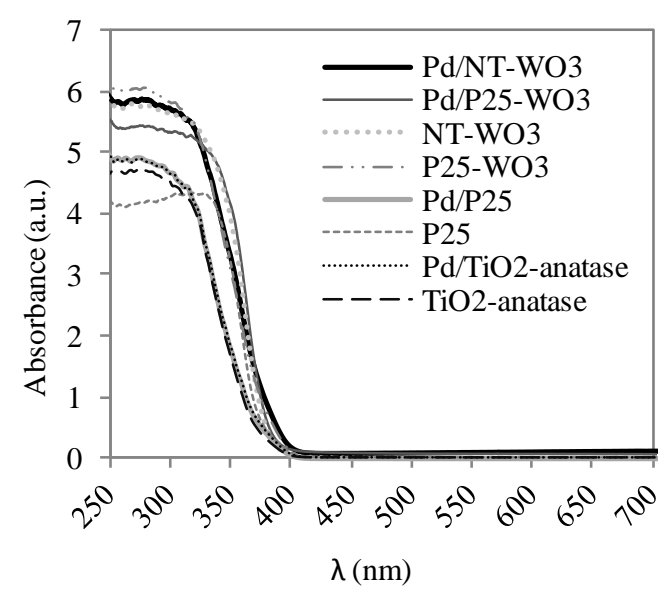

Figure 8. DR UV-Vis spectra of the catalysts

\subsection{Hydrogen production}

Hydrogen test were carried out in both systems, UVA and solar light. The experiments were carried out under different catalyst concentrations and different amounts of methanol. The objective was to determine the optimal set of conditions under which, the hydrogen generation is maximum. Other parameters such as Pd amount deposited, type of water and light source were also studied to understand their effect on the hydrogen evolution.

\subsubsection{Effect of the amount of catalyst and the catalyst nature}

Fig. 9 shows the hydrogen evolution for $\mathrm{Pd} / \mathrm{NT}-\mathrm{WO}_{3}$ and $\mathrm{Pd} / \mathrm{P} 25-\mathrm{WO}_{3}$ under solar light for different catalyst concentration: 86.3 , 166.7, 333.3 and $500 \mathrm{ppm}$. A blank test without catalyst addition was also performed and no generation of hydrogen was observed. For both catalysts, the highest hydrogen evolution was observed for a catalyst concentration of 166.7 ppm. This indicates that there is an optimal catalyst concentration for hydrogen generation. Probably, under these experimental conditions, lower amount of catalyst implies not enough active sites to produce higher amount of hydrogen; and higher amount of catalyst involves higher light dispersion, which also leads to a lower hydrogen generation. Furthermore, $\mathrm{Pd} / \mathrm{NT}-\mathrm{WO} 3$ catalyst showed higher hydrogen evolution than $\mathrm{Pd} / \mathrm{P} 25-\mathrm{WO}_{3}$ catalyst (around $30 \%$ more)

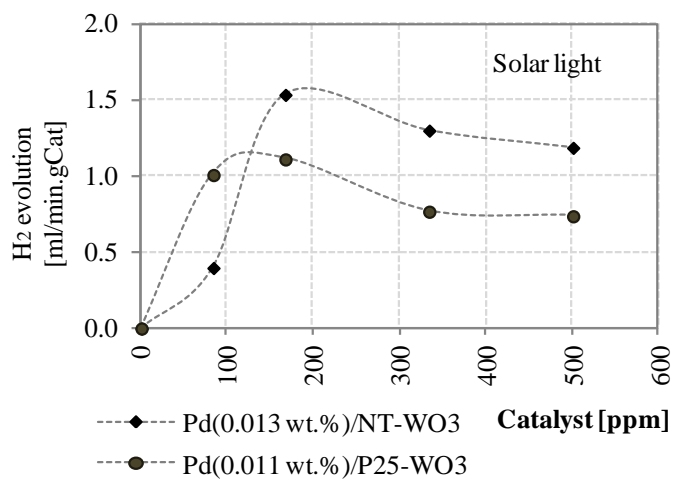

Figure 9. Hydrogen generation versus amount of catalyst. Experimental conditions: $600 \mathrm{ml}$ of water-methanol mixture (50 vol.\%), under simulated solar light (Xe Lamp, 300-800 nm, $250 \mathrm{~W} / \mathrm{m}^{2}$, I $250-450 \mathrm{~nm}: 6.5 \times 10^{-4}$ Einstein/min). 
Fig. 10 shows the hydrogen production for different catalysts based on $\mathrm{Pd}, \mathrm{TiO}_{2}$ and $\mathrm{WO}_{3}$ under solar light. In this experimental set was found that the highest hydrogen production was achieved by $\mathrm{Pd} / \mathrm{NT}-\mathrm{WO} 3(1.57 \mathrm{ml} / \mathrm{min} . \mathrm{gCat})$ followed by $\mathrm{Pd} / \mathrm{P} 25-\mathrm{WO} 3$ ( $1.06 \mathrm{ml} / \mathrm{min} . \mathrm{gCat})$ and $\mathrm{Pd} / \mathrm{P} 25(0.73 \mathrm{ml} / \mathrm{min} . \mathrm{gCat})$. The $\mathrm{NT}-\mathrm{WO}_{3}, \mathrm{P} 25-\mathrm{WO}_{3}$ and $\mathrm{P} 25$ supports scarcely reached $0.499,0.30$ and $0.030 \mathrm{ml} / \mathrm{min} . \mathrm{gCat}$, respectively. These results indicate that the incorporation of this very low amount of Pd improves the efficiency of $\mathrm{NT}-\mathrm{WO}_{3}, \mathrm{P} 25-\mathrm{WO}_{3}$ and $\mathrm{P} 25$ catalysts toward hydrogen production around three times for both $\mathrm{NT}-\mathrm{WO} 3$ and $\mathrm{P} 25-$ $\mathrm{WO}_{3}$, and up to 25 times for $\mathrm{P} 25$. Furthermore, the incorporation of $\mathrm{WO}_{3}$ in the bare $\mathrm{TiO}_{2}$ also increases the hydrogen production.

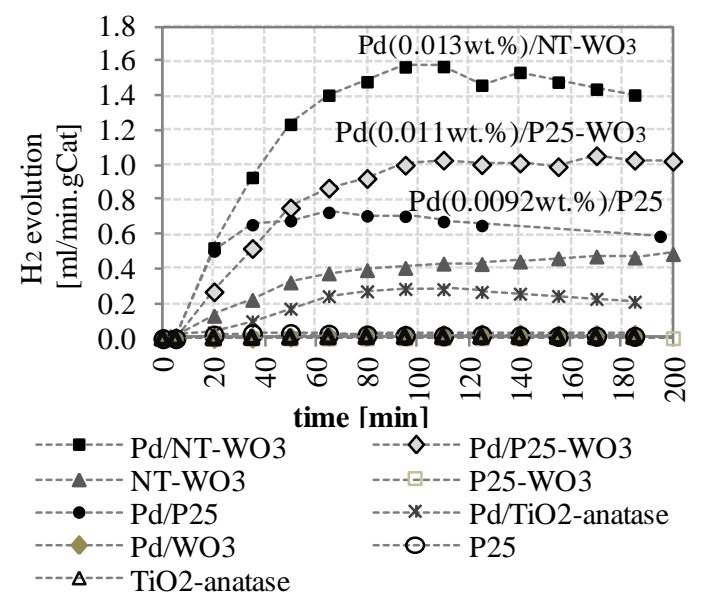

Figure 10. Hydrogen generation varying the catalytic support nature. Experimental conditions: catalyst $167 \mathrm{ppm}, 600 \mathrm{ml}$ of a water-methanol solution (50 vol.\%) under simulated solar light (Xe Lamp, 300-800 nm, $250 \mathrm{~W} / \mathrm{m}^{2}$, I 250-450 nm: 6.5x10 ${ }^{-4}$ Einstein/min).

In Figure 10 it can also be observed that, at the beginning of the irradiation there is an increase in hydrogen evolution before reaching a plateau. This induction period may correspond to the formation of active sites for hydrogen. Some authors explain that this period can correspond to a photocatalytic reduction of an oxidized form of a metallic-co-catalyst [18][36][37] (M ${ }^{+} \rightarrow \mathbf{M}^{0}, \mathbf{M}$ metallic element). Konta et al [36] indicate that this induction periods suggest that some reduction processes are carried out on the catalyst at the beginning of the irradiation. Based on these ideas, it is possible to understand that before irradiation, the Pd on the catalyst could be in an oxidized form (in agreement with the XPS results), then, after starting irradiation, the Pd is becoming reduced by the electrons photogenerated. Hence, with the increasing of irradiation time, more electrons are photogenerated, then, more metallic $\mathrm{Pd}$ is formed $\left(\mathrm{Pd}^{0}\right)$ and more hydrogen ions are adsorbed on the Pd surface.
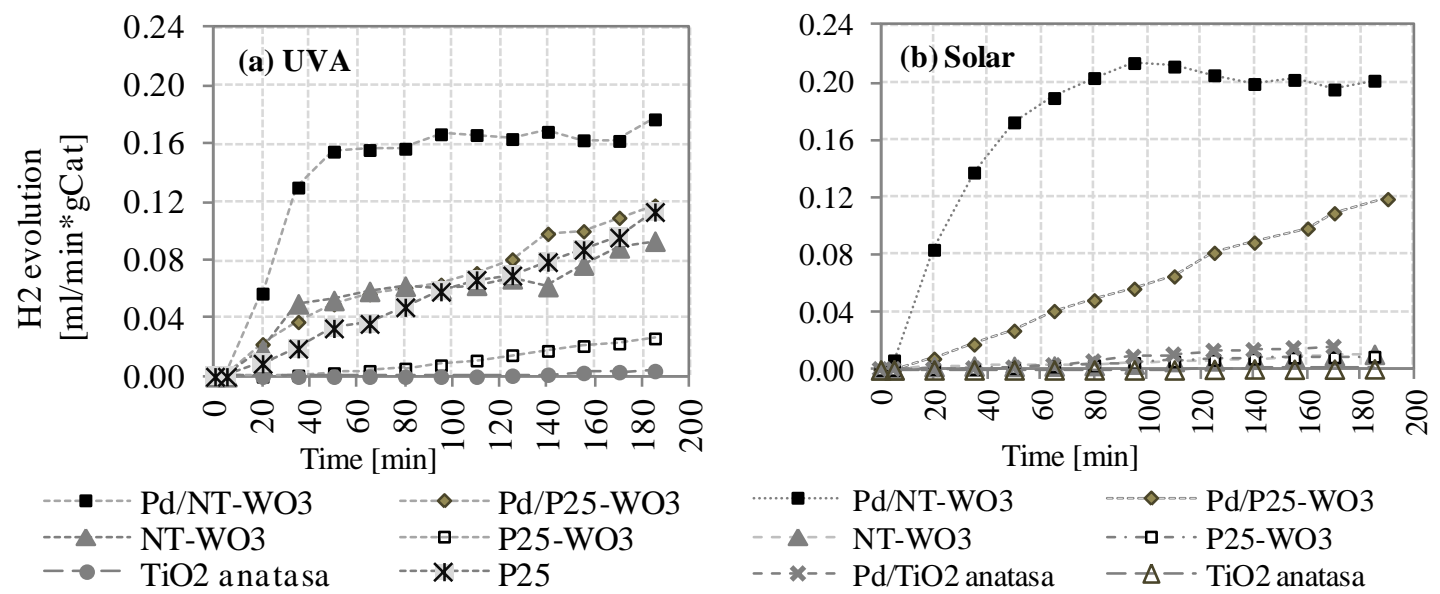

Figure 11. Hydrogen generation varying the catalytic support nature under a) UVA and b) solar light. Experimental conditions: catalyst 500 ppm, $600 \mathrm{ml}$ of a tap water-methanol solution (50 vol.\%) under simulated solar light (Xe Lamp, 300-800 nm, $250 \mathrm{~W} / \mathrm{m}^{2}, \mathrm{I}_{250-450} \mathrm{~nm}: 6.5 \times 10^{-4}$ Einstein/min).

The effect of the catalyst nature was also studied using tap water in the water-methanol solution, but in this case, due to the nature of the tap water which reduces importantly the hydrogen evolution, the catalysts concentration was increased (500 ppm) in this test in order to counteract these hydrogen decrease (Figure 11). 
Similar to the results presented in fig. 12 , the $\mathrm{Pd} / \mathrm{NT}-\mathrm{WO}_{3}$ and $\mathrm{Pd} / \mathrm{P} 25-\mathrm{WO}_{3}$ catalysts showed higher hydrogen generation compared with the rest of catalysts. Concerning the different hydrogen evolution profiles, the catalysts containing Pd present a clear profile with an induction period at the beginning of the reaction followed by a plateau at the end of the experiment. WanTing et al.[18] suggested that this fact can be explained considering that some part of the metal is in oxidized form that can be reduced during the irradiation. Furthermore, for the tap water, the content of salts or chlorine can also have some influence in the reduction of Pd nanoparticles by the irradiation and this process is not completed as it can be observed for most of the catalysts presented in fig 13.

\subsubsection{Effect of the methanol concentration}

In order to understand the effect of different concentration of the sacrificial agent on the hydrogen production, different amount of methanol $(0,5,10$ and $50 \mathrm{vol} \%$ ) was studied. Fig. 12 shows the hydrogen production on $\mathrm{Pd} / \mathrm{NT}-\mathrm{WO} 3$ and $\mathrm{Pd} / \mathrm{P} 25-\mathrm{WO} 3$ at different concentration of methanol. It can be seen that under our experimental conditions, in the absence of methanol, the water splitting did not take place (line corresponding to 0 vol.\%), whose Gibbs free energy is $238 \mathrm{~kJ} / \mathrm{mol}$ [28, 37]. When the sacrificial agent was added, hydrogen was detected and its evolution increased with the increase of the amount of methanol. This outcome might be explained by the fact that methanol molecules act as a hole scavenger in the surface of the catalytic support, therefore, the more methanol is added, the higher the probability of photogenerated holes to be trapped by the organic compounds. As a result, photoexcited electrons are easierly trapped by $\mathrm{Pd}$, increasing the lifetime of the electron-hole pair and increasing the hydrogen generation.

In the literature is not still clear the role of water and organic compound molecules. Some authors have suggested that the reduction of the photogenerated holes may happen when they are transferred directly toward the methanol or by intermediary species such as hydroxyl radicals $(\cdot \mathrm{OH})$ or oxide ions $\left(\mathrm{O}^{2-}\right)$, formed from the oxidation of water molecules or by reduction of remaining oxygen molecules $\left(\mathrm{O}_{2}\right)$ (even after deaeration) that are adsorbed on the photocatalytic surface, or both simultaneously [34]. Other authors proposed that the dissociation of the organic compounds can be complete arriving to $\mathrm{CO}_{2}$ and $\mathrm{H}_{2} \mathrm{O}$, or partial, where the reaction proceeds into the dissociation of next intermediary products [38, 39]. Patsoura et al. [16] explained also that the addition of organic compounds in photocatalytic reactions helps to clean up the catalyst surface from "poisons", which results into a higher hydrogen evolution.

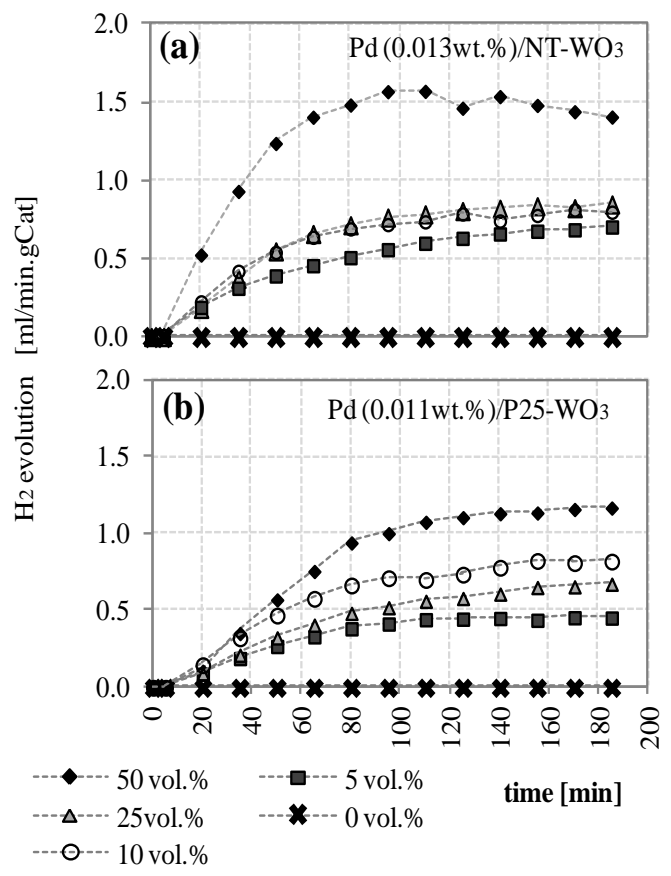

Figure 12. Hydrogen generation varying the concentration of methanol. a) $\mathrm{Pd} / \mathrm{NT}-\mathrm{WO}_{3}$ b) $\mathrm{Pd} / \mathrm{P} 25-\mathrm{WO}_{3}$. Experimental conditions: catalyst

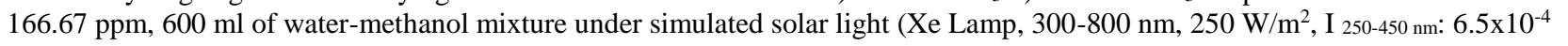
Einstein/min) 


\subsubsection{Effect of the type of water and light source}

Fig 13 presents a comparison, for $\mathrm{Pd} / \mathrm{NT}-\mathrm{WO}_{3}$ and $\mathrm{Pd} / \mathrm{P} 25-\mathrm{WO}_{3}$ catalysts, between the system under UVA and solar light. Respect to the effect of the light source on hydrogen production, under UVA light, the hydrogen evolution for $\mathrm{Pd} / \mathrm{NT}-\mathrm{WO} 3$ and $\mathrm{Pd} / \mathrm{P} 25-$ $\mathrm{WO}_{3}$ were 1.171 and $1.033 \mathrm{ml} / \mathrm{min} . \mathrm{gCat}$, respectively. Under solar light, the hydrogen evolution were 1.122 and 0.723 $\mathrm{ml} / \mathrm{min} . \mathrm{gCat}$, respectively. Under solar light, the significant difference between $\mathrm{Pd} / \mathrm{NT}-\mathrm{WO}_{3}$ and $\mathrm{Pd} / \mathrm{P} 25-\mathrm{WO} 3$ could be due to the different structure of NT, whose band-gap is narrower, therefore it helps to capture more photons from the near visible range, increasing the hydrogen production.

As for the effect of the water matrix, in both figures (Fig. 13 (a) and (b)) is clear the negative effect of the presence of salts in tap water for hydrogen evolution. Under UVA light, the hydrogen evolution using $\mathrm{Pd} / \mathrm{NT}-\mathrm{WO}_{3}$ and $\mathrm{Pd} / \mathrm{P} 25-\mathrm{WO}$, using a milliQwater-methanol solution, is around 7 and 9 times higher than those experiments accomplished with a tap water-methanol solution, respectively. In this case, the quantum efficiency for $\mathrm{Pd} / \mathrm{NT}-\mathrm{WO}_{3}$ and $\mathrm{Pd} / \mathrm{P} 25-\mathrm{WO}_{3}$ decreased from 7.7 to $1.6 \%$ and from 6.2 to $0.9 \%$, respectively. Under solar light, the difference between the hydrogen evolution using milliQ and tap water for the watermethanol solution is around 6 times higher for both catalysts. In this case, the quantum efficiency for Pd/NT-WO and Pd/P25$\mathrm{WO}_{3}$ decreased from 2.3 to $0.4 \%$ and from 1.5 to $0.2 \%$, respectively.

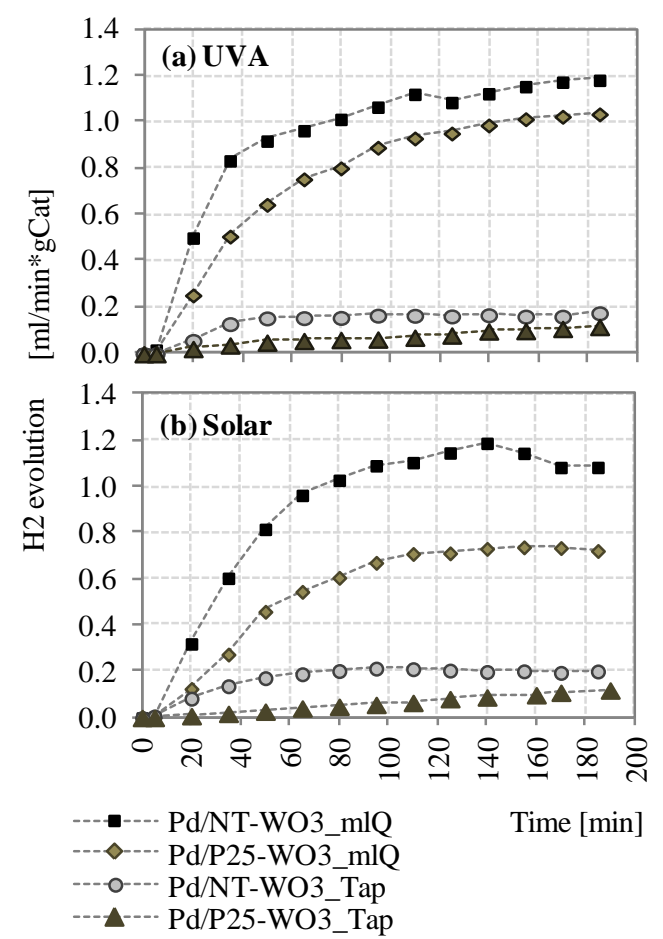

Figure 13. Hydrogen generation varying type of water under a) UVA and b) solar light. Experimental conditions: catalyst $500 \mathrm{ppm}, 250 \mathrm{ml}$ and $600 \mathrm{ml}$ of a water-methanol (50 vol.\%) solution for UVA and solar experiments, respectively.

These results give us a first overview on the challenges to overcome for the hydrogen generation from wastewater treatment. If we are considering using as a source the wastewater from a real wastewater treatment plant, as is still more loaded of impurities and other compounds, they can compete with the generation of hydrogen or deactivate the catalyst.

\subsubsection{Effect of amount of Pd photodeposited}

In order to understand the effect of the amount of Pd photodeposited on the hydrogen evolution, Pd photodeposition was performed, varying the amount of Pd in the catalyst from 0 to $0.03 \mathrm{wt} \%$ concentration. Fig. 14 shows the effect of the amount of 
Pd photodeposited on the hydrogen evolution for three $\mathrm{Pd} / \mathrm{P} 25-\mathrm{WO}_{3}$ catalysts. The amounts of the Pd photodeposited were $0.0075,0.011$ and 0.0297 wt. \%.
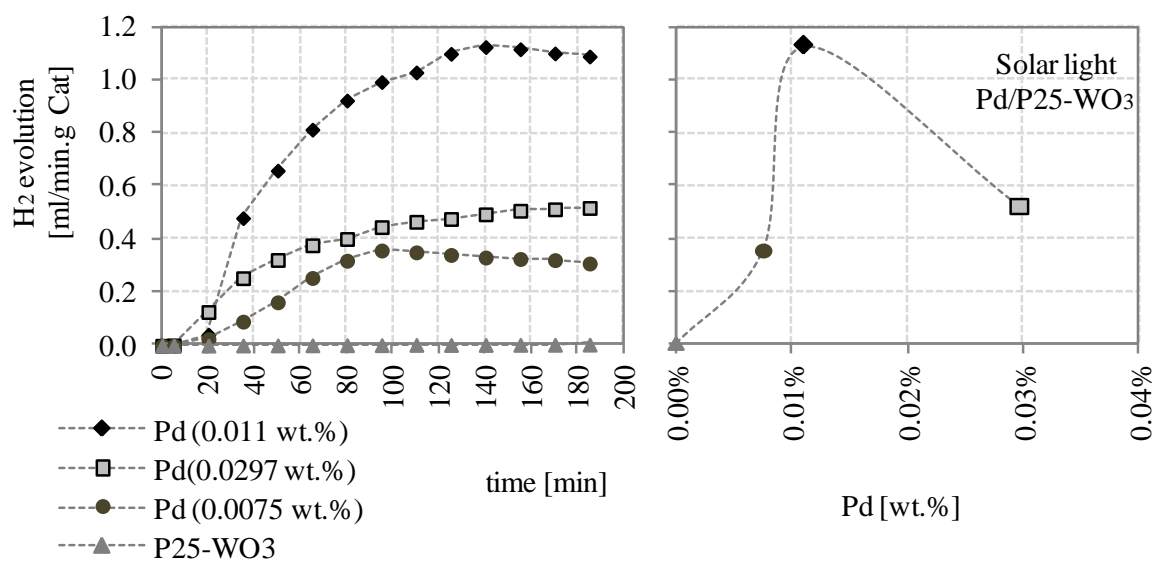

$\operatorname{Pd}[$ wt. $\%]$

Figure 14. Hydrogen generation varying the amount of Pd. Experimental conditions: 166.7 ppm of catalyst, $600 \mathrm{ml}$ of water-methanol mixture under simulated solar light (Xe Lamp, 300-800 nm, $250 \mathrm{~W} / \mathrm{m}^{2}$, I $250-450 \mathrm{~nm}: 6.5 \times 10^{-4}$ Einstein/min).

Concerning the effect of the amount of Pd on the hydrogen generation, Fig. 14 suggests an optimal amount of Pd photodeposited of 0.011 wt \%. For Pd/P25- $\mathrm{WO}_{3}$, the supports without Pd presented very low hydrogen evolutions $(0.004 \mathrm{ml} / \mathrm{min} . \mathrm{gCat})$. When 0.0075 wt.\% of $\mathrm{Pd}$ is added to the catalyst, the hydrogen evolution increases up to a plateau of $0.359 \mathrm{ml} / \mathrm{min} . \mathrm{gCat}$. Once the $\mathrm{Pd}$ is increased until $0.011 \mathrm{wt} \%$, an important increase in the hydrogen evolution was observed (1.125 ml/min.gCat). However, when the Pd added to the photodeposition solution increased to $0.0297 \mathrm{wt} \%$, a decrease was observed in the hydrogen production $(0.519 \mathrm{ml} / \mathrm{min} . \mathrm{gCat})$. Some author explain that the high metal content on catalytic supports could create a shadow effect, therefore the light absorption decrease [38][9].

\section{Literature comparison}

Table 2 shows a comparison of quantum yield values (\%) for hydrogen production obtained by several catalysts based, most of them, on $\mathrm{TiO}_{2}$. Quantum yield (QE or $\phi$ ) [10] and Apparent Quantum efficiency (AQE) [39], [36] determination is found in the literature as follow:

$$
\begin{gathered}
\phi=\frac{\frac{n\left(H_{2} \text { molecules formed }\right)}{\text { unit time }}}{\frac{n(\text { photons exposed })}{\text { unit time }}} .100 \text { eq. (1) } \\
A Q E=\frac{2 n\left(H_{2}\right)}{n(\text { incident photons })} .100 \text { eq. (2) }
\end{gathered}
$$

From eq. (1), $\mathrm{H}_{2}$ molecules formed are calculated from $\mathrm{H}_{2}$ rate (mol/min.gCat), taking into account the amount of catalyst used in a typical photocatalytic experiment and the Avogrado number $\left(6.022 \times 10^{23}\right.$ molecules $\left./ \mathrm{mol}\right)$. The photons exposed are determined taking into account actinometry data, either by Einstein/unit time or Photon/unit time, where one Einstein corresponds to the energy in one mol of photons, therefore $6.022 \times 10^{23}$ photons.

It is significant to mention that quantum yield parameter is only an indicative value of the hydrogen evolution per unit of photons incoming to the photocatalytic system; therefore, the comparison based in this parameter does not take into account experimental conditions such as the amount of catalyst, the content of metal or the reaction volume. 
Table 2. Comparison of quantum yield for hydrogen production ${ }^{\mathrm{a}}$ for different photocatalytic materials.

\begin{tabular}{|c|c|c|c|c|}
\hline Catalyst & Irradiation & Sacrificial Agent & $\begin{array}{c}\mathrm{H}_{2} \\
\text { Rate[mol/min.g } \\
\text { Cat }]\end{array}$ & $\underset{\Phi^{\text {a }}}{\text { Quantum Yield (\%) }}$ \\
\hline $\mathrm{Pd}(0.013$ wt. $\%) / \mathrm{NT}-\mathrm{WO}_{3}$ & \multirow{2}{*}{ Solar (300-800nm) } & \multirow{2}{*}{$\begin{array}{l}\text { Methanol (50 vol.\%) in } \\
500 \text { ppm of catalyst/0.6 L }\end{array}$} & $5.3 \times 10^{-5}$ & 2.3 \\
\hline $\mathrm{Pd}(0.011$ wt. $\%) / \mathrm{P} 25-\mathrm{WO}_{3}$ & & & $3.3 \times 10^{-5}$ & 1.5 \\
\hline $\operatorname{Pd}(0.013$ wt. $\%) / \mathrm{NT}-\mathrm{WO}_{3}$ & \multirow{2}{*}{ UVA $(300-400 \mathrm{~nm})$} & \multirow{2}{*}{$\begin{array}{c}\text { Methanol (50 vol.\%) in } \\
500 \mathrm{ppm} \text { of catalyst/0.25 L }\end{array}$} & $5.3 \times 10^{-5}$ & 7.7 \\
\hline $\mathrm{Pd}(0.011$ wt. $\%) / \mathrm{P} 25-\mathrm{WO}_{3}$ & & & $4.7 \times 10^{-5}$ & 6.2 \\
\hline \multirow{2}{*}{$\mathrm{Pt}(0.5$ wt.\%)/TiO $2[23]$} & \multirow{2}{*}{ Visible } & $\mathrm{ClCH}_{2} \mathrm{COOH} 0.001 \mathrm{M}$ in $0.1 \mathrm{~L}$ & $5.6 \times 10^{-6}$ & 2.33 \\
\hline & & $\mathrm{Cl}_{2} \mathrm{CHCOOH} 0.001 \mathrm{M}$ in $0.1 \mathrm{~L}$ & $1.5 \times 10^{-6}$ & 0.62 \\
\hline $\mathrm{Pt}(0.5$ wt.\%)/TiO $2[16]$ & Solar & $\begin{array}{l}\text { Water-methanol } \\
0.85 \mathrm{mM} / 0.06 \mathrm{~L}\end{array}$ & $4.6 \times 10^{-6}$ & 0.47 \\
\hline $\mathrm{Pd}(0.5$ wt. $\%) / \mathrm{TiO}_{2}[40]$ & $\begin{array}{l}\text { UV } 365 \mathrm{~nm} \\
\text { UV flux } \\
5.1 \mathrm{~mW} / \mathrm{cm}^{2}\end{array}$ & $\begin{array}{c}\text { Alcohol:Methanol } \\
(10 \text { vol.\%)/0.20 L } \\
\text { Alcohol: methanol, ethanol, 2-propanol, } \\
\text { tertbutanol, 1,2-ethanediol (2), 1,2- } \\
\text { propanediol and glycerol (1) }\end{array}$ & $6.9 \times 10^{-4}(1)$ & - \\
\hline \multirow{2}{*}{$\mathrm{Pd}(1$ wt. $\%) / \mathrm{TiO}_{2}[40]$} & \multirow{4}{*}{$\begin{array}{c}\text { Solar spectrum } \\
\text { 150 W Xe arc lamp } \\
\text { solar simulator with } \\
\text { not filter }\end{array}$} & \multirow{4}{*}{$\begin{array}{c}\text { MetOH (1) } \\
\text { Triethanolamine (2) } \\
0.125 \mathrm{M}\end{array}$} & $5.78 \times 10^{-4}(2)$ & - \\
\hline & & & $7.9 \times 10^{-4}(1)$ & - \\
\hline \multirow{2}{*}{$\begin{array}{c}\mathrm{Pd}(1 \text { wt. } \%) / \mathrm{TiO}_{2}[40] \\
\mathrm{Pd}(0.5 \text { wt. } \%) / \mathrm{TiO}_{2}[41]\end{array}$} & & & $7.41 \times 10^{-4}(2)$ & - \\
\hline & & & $2.7 \times 10^{-5}$ & - \\
\hline $\mathrm{Pd}(0.1 \mathrm{~mol} \%) / \mathrm{TiO}_{2}[27]$ & $\begin{array}{c}\text { UV } 365 \mathrm{~nm} \\
\text { lamps } 18 \mathrm{~W} / \mathrm{cm}^{2}\end{array}$ & Water:MetOH (1:1) & $4.1 \times 10^{-7}$ & - \\
\hline
\end{tabular}

${ }^{\text {a }}$ Quantum yield[10], [42], [39]

Table 2 shows different catalysts based on noble metals ( $\mathrm{Pd}$ or $\mathrm{Pt}$ ) supported on $\mathrm{TiO}_{2}$. The first four catalysts are those studied in this paper. Regarding the results of the quantum yield $(\varphi)$ under UVA light, the catalysts studied in this paper seem to be enough good, 7.7 and $6.2 \%$ for $\mathrm{Pd} / \mathrm{NT}-\mathrm{WO}_{3}$ and $\mathrm{Pd} / \mathrm{P} 25-\mathrm{WO}_{3}$, respectively, compared to the literature. However, under solar light, the efficiencies appear still low, 2.3 and $1.5 \%$. Despite this fact, it is important to highlight that in the literature, the amount of metal deposited on most of the supports is between 0.5-1 wt \%. On the other hand, our catalysts metal loading is around $0.01 \mathrm{wt} \%$. This factor might become our competitive point, if we take into account the high price of palladium.

\section{Conclusions}

This study presents the hydrogen generation from water-methanol mixtures on a series of $\mathrm{Pd} / \mathrm{TiO}_{2}-\mathrm{WO}_{3}$ and $\mathrm{Pd} / \mathrm{P} 25$ catalysts, containing a very low amount of Pd (around $0.01 \mathrm{wt} \%$ ) prepared by photodeposition. It was observed that the introduction of Pd on all the supports produced an important increase in the rate of hydrogen evolution, despite the small amounts of Pd photodeposited. Regarding the absence/presence and the roll of sacrificial agents in photocatalytic hydrogen production, under our experimental conditions, this study concludes that hydrogen generation by water splitting is practically null. On the other hand, when methanol is added, an important improvement in the hydrogen generation was obtained. The amount of hydrogen generated increases with the increase of the methanol concentration. This fact reveals the importance of sacrificial agents in the efficiency of hydrogen generation. Sacrificial agents likely act as holes scavenger, so the recombination probability is reduced.

When Pd was incorporated in different amount $(0.0075,0.011$ and 0.0297 wt.\%) the hydrogen generation was affected significantly, and it is possible to see an optimum value of Pd (around 0.01wt.\%). These results might be related to the way Pd is deposited on the support, that affects size, dispersion, morphology, etc. of the catalysts. It reveals that it is essential a further study 
about the Pd photodeposition method on the different catalytic supports (NT- $\mathrm{WO}_{3}, \mathrm{P} 25-\mathrm{WO}_{3}$ and $\left.\mathrm{P} 25\right)$ using high resolution techniques that can provide valuable information for smaller particles of $\mathrm{Pd}$ (lower than $2 \mathrm{~nm}$ ).

The best supports for hydrogen generation under both, solar and UVA light, have been $\mathrm{NT}-\mathrm{WO}_{3}$ and $\mathrm{P}_{2} 5-\mathrm{WO}_{3}$, whose hydrogen productions under solar light were: $1.18(\varphi: 2.3 \%)$ and $0.7389 \mathrm{ml} / \mathrm{min} . \mathrm{gCat}(\varphi: 1.5 \%)$, respectively, and under UVA light: 1.19 $(\varphi: 7.7 \%)$ and $1.03 \mathrm{ml} / \mathrm{min} . \mathrm{gCat}(\varphi: 6.16 \%)$, respectively.

In view of the visible light response of the $\mathrm{NT}-\mathrm{WO}_{3}$ and $\mathrm{P} 25-\mathrm{WO}_{3}$ catalysts with $\mathrm{Pd}$ incorporated, it is highly necessary to continue the study to improve the Pd deposition method and their quantum efficiencies. This study demonstrates that the incorporation of very low amount of Pd by photodeposition can improve the hydrogen generation with results comparable to other catalysts already presented in the literature that contained a higher amount of Pd (higher than 0.5 wt \%). This fact is of special interest for a real application considering the high price of $\mathrm{Pd}$.

\section{Acknowledgments}

This work has been supported by the Spanish Ministry of Economy and Competitiveness (MINECO) through the projects CTQ2012-37039-C02-02 and CTM2015-71054-REDT. JL is a Serra Húnter Fellow and is grateful to ICREA Academia program and grants MINECO/FEDER ENE2015-63969-R and GC 2017 SGR 128.

\section{References}

[1] K. Villa, X. Domènech, S. Malato, M.I. Maldonado, J. Peral, Heterogeneous photocatalytic hydrogen generation in a solar pilot plant, Int. J. Hydrogen Energy. 38 (2013) 12718-12724. doi:10.1016/j.ijhydene.2013.07.046.

[2] É. Karácsonyi, L. Baia, a. Dombi, V. Danciu, K. Mogyorósi, L.C. Pop, G. Kovács, V. Coşoveanu, a. Vulpoi, S. Simon, Z. Pap, The photocatalytic activity of $\mathrm{TiO} / \mathrm{WO} 3 /$ noble metal ( $\mathrm{Au}$ or $\mathrm{Pt}$ ) nanoarchitectures obtained by selective photodeposition, Catal. Today. 208 (2013) 19-27. doi:10.1016/j.cattod.2012.09.038.

[3] I. Dincer, C. Acar, Review and evaluation of hydrogen production methods for better sustainability, Int. J. Hydrogen Energy. (2015). doi:10.1016/j.ijhydene.2014.12.035.

[4] A Fujishima, K. Honda, TiO2 photoelectrochemistry and photocatalysis, Nature. 213 (1972) 8656. https://electrochem.org/d1/ma/203/pdfs/2729.pdfาnpapers2://publication/uuid/F6B805BA-46E0-443A-B6664F5841D3D337.

[5] X. Chen, S. Shen, L. Guo, S.S. Mao, Semiconductor-based Photocatalytic Hydrogen Generation., Chem. Rev. (Washington, DC, United States). 110 (2010) 6503-6570. doi:10.1021/cr1001645.

[6] H. Kato, K. Asakura, A. Kudo, Highly efficient water splitting into H2 and O2 over lanthanum-doped NaTaO3 photocatalysts with high crystallinity and surface nanostructure, J. Am. Chem. Soc. 125 (2003) 3082-3089. doi:10.1021/ja027751g.

[7] K. Maeda, D. Lu, K. Domen, Direct water splitting into hydrogen and oxygen under visible light by using modified taon photocatalysts with d0 electronic configuration, Chem. - A Eur. J. 19 (2013) 4986-4991. doi:10.1002/chem.201300158.

[8] R. Molinari, C. Lavorato, P. Argurio, Recent progress of photocatalytic membrane reactors in water treatment and in synthesis of organic compounds. A review, Catal. Today. 281 (2017) 144-164. doi:10.1016/j.cattod.2016.06.047. 
F.J. Lopez-Tenllado, J. Hidalgo-Carrillo, V. Montes, a. Marinas, F.J. Urbano, J.M. Marinas, L. Ilieva, T. Tabakova, F. Reid, A comparative study of hydrogen photocatalytic production from glycerol and propan-2-ol on M/TiO2 systems (M=Au, Pt, Pd), Catal. Today. 280 (2017) 58-64. doi:10.1016/j.cattod.2016.05.009.

[10] Y.Z. Yang, C.H. Chang, H. Idriss, Photo-catalytic production of hydrogen form ethanol over M/TiO2 catalysts ( $\mathrm{M}=\mathrm{Pd}$, Pt or Rh), Appl. Catal. B Environ. 67 (2006) 217-222. doi:10.1016/j.apcatb.2006.05.007.

[11] H.J. Choi, M. Kang, Hydrogen production from methanol/water decomposition in a liquid photosystem using the anatase structure of Cu loaded TiO2, Int. J. Hydrogen Energy. 32 (2007) 3841-3848. doi:10.1016/j.ijhydene.2007.05.011.

[12] M. Pelaez, N.T. Nolan, S.C. Pillai, M.K. Seery, P. Falaras, A.G. Kontos, P.S.M. Dunlop, J.W.J. Hamilton, J.A. Byrne, K. O’Shea, M.H. Entezari, D.D. Dionysiou, A review on the visible light active titanium dioxide photocatalysts for environmental applications, Appl. Catal. B Environ. 125 (2012) 331-349. doi:10.1016/j.apcatb.2012.05.036.

[13] M. De Oliveira Melo, L.A. Silva, Photocatalytic production of hydrogen: An innovative use for biomass derivatives, J. Braz. Chem. Soc. 22 (2011) 1399-1406. doi:10.1590/S0103-50532011000800002.

[14] H. Tong, S. Ouyang, Y. Bi, N. Umezawa, M. Oshikiri, J. Ye, Nano-photocatalytic materials: Possibilities and challenges, Adv. Mater. 24 (2012) 229-251. doi:10.1002/adma.201102752.

[15] I. Kampus, U.I. Depok, I. E-mail, Photocatalytic Hydrogen Generation from Glycerol and Water using Pt loaded N-doped TiO 2 Nanotube, Int. J. Eng. Technol. 11 (2011) 91-95.

[16] A. Patsoura, D.I. Kondarides, X.E. Verykios, Photocatalytic degradation of organic pollutants with simultaneous production of hydrogen, Catal. Today. 124 (2007) 94-102. doi:10.1016/j.cattod.2007.03.028.

[17] Y. Li, G. Lu, S. Li, Photocatalytic hydrogen generation and decomposition of oxalic acid over platinized TiO2, Appl. Catal. A Gen. 214 (2001) 179-185. doi:10.1016/S0926-860X(01)00491-4.

[18] W.-T. Chen, A. Chan, D. Sun-Waterhouse, T. Moriga, H. Idriss, G.I.N. Waterhouse, Ni/TiO2: A promising low-cost photocatalytic system for solar H2 production from ethanol-water mixtures, J. Catal. 326 (2015) 43-53. doi:10.1016/j.jcat.2015.03.008.

[19] H. Yan, J. Yang, G. Ma, G. Wu, X. Zong, Z. Lei, J. Shi, C. Li, Visible-light-driven hydrogen production with extremely high quantum efficiency on Pt-PdS/CdS photocatalyst, J. Catal. 266 (2009) 165-168. doi:10.1016/j.jcat.2009.06.024.

[20] V.M. Daskalaki, M. Antoniadou, G. Li Puma, D.I. Kondarides, P. Lianos, Solar light-responsive Pt/CdS/TiO2 photocatalysts for hydrogen production and simultaneous degradation of inorganic or organic sacrificial agents in wastewater, Environ. Sci. Technol. 44 (2010) 7200-7205. doi:10.1021/es9038962.

[21] H. Zhou, J. Pan, L. Ding, Y. Tang, J. Ding, Q. Guo, T. Fan, D. Zhang, Biomass-derived hierarchical porous CdS/M/TiO2 ( $\mathrm{M}=\mathrm{Au}, \mathrm{Ag}, \mathrm{pt}, \mathrm{pd})$ ternary heterojunctions for photocatalytic hydrogen evolution, Int. J. Hydrogen Energy. 39 (2014) 16293-16301. doi:10.1016/j.ijhydene.2014.08.032.

[22] X. Wang, X.Y. Li, Photocatalytic hydrogen generation with simultaneous organic degradation by a visible light-driven CdS/ZnS film catalyst, Mater. Sci. Eng. B Solid-State Mater. Adv. Technol. 181 (2014) 86-92. doi:10.1016/j.mseb.2013.11.015. 
[23] Y. Li, Y. Xie, S. Peng, G. Lu, S. Li, Photocatalytic hydrogen generation in the presence of chloroacetic acids over Pt/TiO2, Chemosphere. 63 (2006) 1312-1318. doi:10.1016/j.chemosphere.2005.09.004.

[24] A. Rey, P. García-Muñoz, M.D. Hernández-Alonso, E. Mena, S. García-Rodríguez, F.J. Beltrán, WO3-TiO2 based catalysts for the simulated solar radiation assisted photocatalytic ozonation of emerging contaminants in a municipal wastewater treatment plant effluent, Appl. Catal. B Environ. 154-155 (2014) 274-284. doi:10.1016/j.apcatb.2014.02.035.

[25] A. Fujii, Z. Meng, C. Yogi, T. Hashishin, T. Sanada, K. Kojima, Preparation of Pt-loaded WO3 with different types of morphology and photocatalytic degradation of methylene blue, Surf. Coatings Technol. 271 (2015) 251-258. doi:10.1016/j.surfcoat.2014.11.070.

[26] Y. Sakai, A. Shimanaka, M. Shioi, S. Kato, S. Satokawa, T. Kojima, A. Yamasaki, Fabrication of high-sensitivity palladium loaded tungsten trioxide photocatalyst by photodeposite method, Catal. Today. 241 (2015) 2-7. doi:10.1016/j.cattod.2014.07.044.

[27] B.S. Kwak, J. Chae, J. Kim, M. Kang, Enhanced Hydrogen Production from Methanol / Water Photo-Splitting in TiO 2 Including Pd Component, Bull. Korean Chem. Soc. 30 (2009). doi:0253-2964.

[28] A. a. Ismail, D.W. Bahnemann, Photochemical splitting of water for hydrogen production by photocatalysis: A review, Sol. Energy Mater. Sol. Cells. 128 (2014) 85-101. doi:10.1016/j.solmat.2014.04.037.

[29] K.S.W. Sing, D.H. Everett, R. a. W. Haul, L. Moscou, R. a. Pierotti, J. Rouquérol, T. Siemieniewska, INTERNATIONAL UNION OF PURE COMMISSION ON COLLOID AND SURFACE CHEMISTRY INCLUDING CATALYSIS * REPORTING PHYSISORPTION DATA FOR GAS / SOLID SYSTEMS with Special Reference to the Determination of Surface Area and Porosity, Pure Appl. Chem. 54 (1982) 2201-2218. doi:10.1351/pac198557040603.

[30] L. Ouyang, P.F. Tian, G.J. Da, X.C. Xu, C. Ao, T.Y. Chen, R. Si, J. Xu, Y.F. Han, The origin of active sites for direct synthesis of $\mathrm{H}<\mathrm{inf}>2</ \mathrm{inf}>\mathrm{O}<\mathrm{inf}>2</ \mathrm{inf}>$ on $\mathrm{Pd} / \mathrm{TiO}<\mathrm{inf}>2</ \mathrm{inf}>$ catalysts: Interfaces of $\mathrm{Pd}$ and $\mathrm{PdO}$ domains, J. Catal. 321 (2015) 70-80. doi:10.1016/j.jcat.2014.10.003.

[31] M. Shibuya, M. Miyauchi, Site-selective deposition of metal nanoparticles on aligned WO3 nanotrees for superhydrophilic thin films, Adv. Mater. 21 (2009) 1373-1376. doi:10.1002/adma.200802918.

[32] D. Zhang, Visible light-induced photocatalysis through surface plasmon excitation of platinum-metallized titania for photocatalytic bleaching of rhodamine B, Monatshefte Fur Chemie. 143 (2012) 729-738. doi:10.1007/s00706-011-06312.

[33] R. Abe, Recent progress on photocatalytic and photoelectrochemical water splitting under visible light irradiation, J. Photochem. Photobiol. C Photochem. Rev. 11 (2010) 179-209. doi:10.1016/j.jphotochemrev.2011.02.003.

[34] R.J. Candal, W. Estrada, El fotocatalizador : síntesis, propiedades y limitaciones, Tecnol. Solares Para La Desinfección Y Descontaminación Del Agua. (2005) 129-145. https://www.psa.es/webesp/projects/solarsafewater/curso.php.

[35] X. Zhang, M. Yang, J. Zhao, L. Guo, Photocatalytic hydrogen evolution with simultaneous degradation of organics over (CuIn)0.2Zn1.6S2 solid solution, Int. J. Hydrogen Energy. 38 (2013) 15985-15991. doi:10.1016/j.ijhydene.2013.10.014. 
[36] R. Konta, T. Ishii, H. Kato, A. Kudo, Photocatalytic Activities of Noble Metal Ion Doped SrTiO 3 under Visible Light Irradiation, (2004) 8992-8995.

[37] J.F. Reber, K. Meier, Photochemical Production of Hydrogen with Zinc-Sulfide Suspensions, J. Phys. Chem. 88 (1984) 5903-5913. <Go to ISI>://A1984TU20800032.

[38] Slamet, Ratnawati, J. Gunlazuardi, E.L. Dewi, Enhanced photocatalytic activity of Pt deposited on titania nanotube arrays for the hydrogen production with glycerol as a sacrificial agent, Int. J. Hydrogen Energy. 42 (2017) 24014-24025. doi:10.1016/j.ijhydene.2017.07.208.

[39] R. Su, R. Tiruvalam, A.J. Logsdail, Q. He, C. a Downing, M.T. Jensen, N. Dimitratos, L. Kesavan, P.P. Wells, R. Bechstein, H.H. Jensen, S. Wendt, C.R. a Catlow, C.J. Kiely, G.J. Hutchings, F. Besenbacher, Designer titania-supported Au-Pd nanoparticles for efficient photocatalytic hydrogen production., ACS Nano. 8 (2014) 3490-7. doi:10.1021/nn500963m.

[40] Z.H.N. Al-Azri, W.T. Chen, A. Chan, V. Jovic, T. Ina, H. Idriss, G.I.N. Waterhouse, The roles of metal co-catalysts and reaction media in photocatalytic hydrogen production: Performance evaluation of $\mathrm{M} / \mathrm{TiO}<\mathrm{inf}>2</ \mathrm{inf}>$ photocatalysts $(\mathrm{M}$ $=$ Pd, Pt, Au) in different alcohol-water mixtures, J. Catal. 329 (2015) 355-367. doi:10.1016/j.jcat.2015.06.005.

[41] W. Jones, D.J. Martin, A. Caravaca, A.M. Beale, M. Bowker, T. Maschmeyer, G. Hartley, A. Masters, A comparison of photocatalytic reforming reactions of methanol and triethanolamine with Pd supported on titania and graphitic carbon nitride., Appl. Catal. B Environ. (2017) 1-7. doi:10.1016/j.apcatb.2017.01.042.

[42] N. Strataki, V. Bekiari, D.I. Kondarides, P. Lianos, Hydrogen production by photocatalytic alcohol reforming employing highly efficient nanocrystalline titania films, Appl. Catal. B Environ. 77 (2007) 184-189. doi:10.1016/j.apcatb.2007.07.015. 